Supporting Information for:

\title{
Kinetically Controlled Sequential Seeded Growth: A General Route to Crystals with Different Hierarchies
}

Joshua D. Smith, Mattea M. Scanlan, Alexander N. Chen, Hannah M. Ashberry, and Sara E. Skrabalak*

Department of Chemistry, Indiana University - Bloomington, 800 E. Kirkwood Avenue, Bloomington, IN 47405, USA 


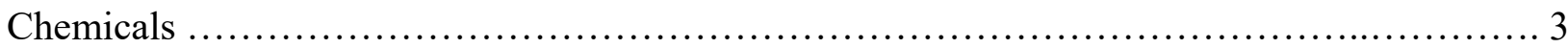

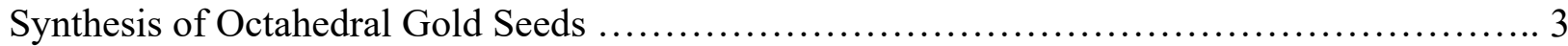

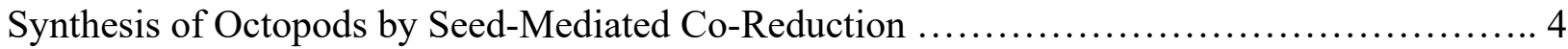

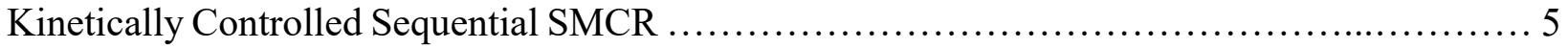

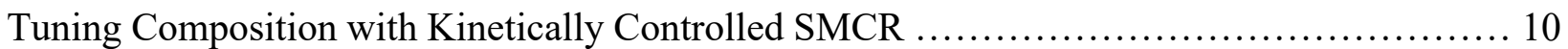

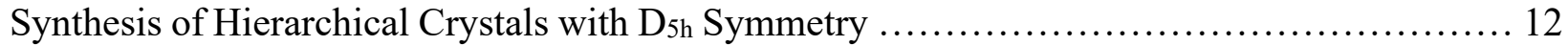

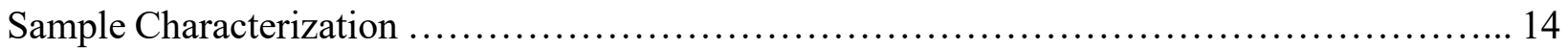

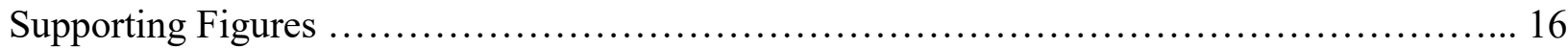

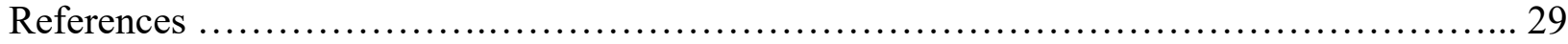




\section{Chemicals}

Gold(III) chloride trihydrate $\left(\mathrm{HAuCl}_{4} \cdot 3 \mathrm{H}_{2} \mathrm{O}, \geq 99.9 \%\right)$, L-ascorbic acid (L-AA, BioUltra, $\geq 99.0 \%$ ), hexadecyltrimethylammonium bromide (CTAB, BioUltra, $\geq 99.0$ ), sodium citrate tribasic dihydrate $\left(\mathrm{Na}_{3} \mathrm{Citrate} \cdot 2 \mathrm{H}_{2} \mathrm{O}\right.$, BioUltra, $\left.\geq 99.5 \%\right)$, cetyltrimethylammonium chloride solution (CTAC, $25 \mathrm{wt} \%)$, sodium bromide $(\mathrm{NaBr}, \quad$ BioUltra, $\geq 99.5 \%)$, bis(psulfonatophenyl)phenylphosphine dihydrate dipotassium salt (BSPP, 97\%), silver nitrate $\left(\mathrm{AgNO}_{3}\right.$, $\geq 99.999 \%$ ), and palladium(II) chloride ( $\mathrm{PdCl}_{2}, \geq 99.9 \%$ ) were purchased from Sigma Aldrich. 1N hydrochloric acid $(\mathrm{HCl})$ was purchased from Fisher Chemical. Acetone (ACS grade), methanol (ACS grade), and isopropanol (ACS grade) were purchased from Macron. All chemicals were used as received without further purification. All vials were rinsed with ethanol and dried with air prior to use. Milli-Q nanopure water $(18.2 \mathrm{M} \Omega \mathrm{cm})$ was used in all experiments. An aqueous $10 \mathrm{mM}$ $\mathrm{H}_{2} \mathrm{PdCl}_{4}$ solution was prepared by heating at $\sim 70{ }^{\circ} \mathrm{C}$ and stirring dissolved $\mathrm{PdCl}_{2}(44.6 \mathrm{mg})$ in 25 $\mathrm{mL}$ of $\mathrm{HCl}(\mathrm{pH} 1.69)$ for $1 \mathrm{~h}{ }^{1}$

\section{Synthesis of Octahedral Gold Seeds}

$\mathrm{Au}$ octahedra were synthesized with minor adaptations to a previously reported hydrothermal method. ${ }^{1} \mathrm{In}$ a $30 \mathrm{~mL}$ vial, a growth solution of $0.250 \mathrm{~mL}$ of $10 \mathrm{mM} \mathrm{HAuCl}{ }_{4} \cdot 3 \mathrm{H}_{2} \mathrm{O}$, $1.5 \mathrm{~mL}$ of $100 \mathrm{mM} \mathrm{CTAB}$, and $0.050 \mathrm{~mL}$ of $100 \mathrm{mM} \mathrm{Na}_{3}$ Citrate was diluted with $8.2 \mathrm{~mL}$ of water. Solutions were gently swirled to mix and then allowed to mature in an oil bath at $110{ }^{\circ} \mathrm{C}$ for $24 \mathrm{~h}$. $\mathrm{Au}$ octahedra were collected by centrifugation $(10,000 \mathrm{rpm} / 12,000 \mathrm{~g})$ for $10 \mathrm{~min}$, removed from supernatant, and diluted to a volume of $3 \mathrm{~mL}$ with water. Octahedral Au solutions were standardized to 0.18 (abs.) at $400 \mathrm{~nm}$ with a $\lambda_{\max } \approx 550 \mathrm{~nm}$.

Troubleshooting: 
1. Octahedra should result in a wine-red colored solution. Deviations are commonly observed when i) the CTAB is bad or ii) the cap is not sealed properly. If CTAB is bad, then recrystallizing the $\mathrm{CTAB}$ will help. Using a high purity sodium citrate ( $>99 \%)$ is important for reproducibility purposes.

2. The presence of a blue-orange solution has either larger octahedra or a high population of triangular plates (a common side product). A light pink solution is indicative of small octahedra and sphere-like nanoparticles. Note that changing synthetic parameters will result in different octahedra sizes and sample uniformity.

3. Reaction is sensitive to $\mathrm{pH}$. These reactions were performed in disposable glass vials that were rinsed with ethanol. Make sure that the vials are dried completely before use. Do not rinse with acid. Further optimization is required for reusable glassware.

4. Vials are commonly inverted to ensure mixing. We found the best results occur from gently swirling the solution.

5. The addition of water, $\mathrm{HAuCl}_{4}, \mathrm{CTAB}$, and sodium citrate in this order was found to be optimal for this synthesis.

6. This reaction is robust and should result in octahedra approximately 9/10 times.

\section{Synthesis of Octopods by Seed-Mediated Co-Reduction}

Seed-mediated co-reduction (SMCR) was performed as previously described with modifications. $^{2}$ A growth solution containing $20.0 \mathrm{~mL}$ of $\mathrm{H}_{2} \mathrm{O}, 2.0 \mathrm{~mL}$ of $200 \mathrm{mM}$ CTAB, 50 $\mu \mathrm{L} 100 \mathrm{mM} \mathrm{HAuCl}_{4} \cdot 3 \mathrm{H}_{2} \mathrm{O}$, and $100 \mu \mathrm{L}$ of $10 \mathrm{mM} \mathrm{H}_{2} \mathrm{PdCl}_{4}$ was added to a $30 \mathrm{~mL}$ reaction vial. The solutions were gently inverted to mix and $1.5 \mathrm{~mL}$ of freshly prepared $100 \mathrm{mM} \mathrm{L}-\mathrm{AA}$ was added. To this solution, $600 \mu \mathrm{L}$ Au octahedra dispersion was added. After the addition of the Au seeds, the reaction vial was inverted twice and placed in an oil bath at $25^{\circ} \mathrm{C}$ for $12 \mathrm{~h}$. The stellated 
$\mathrm{Au} / \mathrm{Pd}$ nanostructures were collected by centrifugation $(10000 \mathrm{rpm} / 12000 \mathrm{~g})$ for $15 \mathrm{~min}$, removed from supernatant and dispersed in $3 \mathrm{~mL}$ of water. The octopod solution was standardized by UVVis with an absorbance of 0.38 at $400 \mathrm{~nm}$ and an LSPR peak around $830 \mathrm{~nm}$.

The octopods synthesized in Supplemental Figure 6.2 were achieved by adding different volume of octahedral seed solution. Octopods with tip-to-tip widths of $90 \mathrm{~nm}$ were achieved with $1.00 \mathrm{~mL}$ of seeds, $104 \mathrm{~nm}$ with $0.90 \mathrm{~mL}$ of seeds, 118 with $0.80 \mathrm{~mL}$ of seeds, and $150 \mathrm{~nm}$ with $600 \mathrm{~mL}$ of seeds.

Troubleshooting:

1. The synthesis of octopods can be successfully scaled up to 10x the reported volumes. Furthermore, the reaction can be scaled down to $1 / 5^{\text {th }}$ the original volume.

2. Octopod solution should have a gray/black color. Holding the solution to light should reveal a blue gray color.

3. Reaction is sensitive to $\mathrm{pH}$. Do not rinse with acid. Further optimization is required for reusable glassware.

4. It is important to allow the precursors adequate time to reduce before introducing seeds. It is recommended to wait 15 seconds before adding seeds to the growth solution.

\section{Kinetically Controlled Sequential SMCR}

Sequential SMCR was performed as previously described with modifications. Similar to previously described $\mathrm{SMCR}, 2,3$ a growth solution containing $20.0 \mathrm{~mL}$ of $\mathrm{H}_{2} \mathrm{O}, 3.0 \mathrm{~mL}$ of $200 \mathrm{mM}$ CTAB or $200 \mathrm{mM} \mathrm{CTAC}$ and $2.0 \mathrm{~mL}$ of $\mathrm{NaBr}$, a volume of $100 \mathrm{mM} \mathrm{HAuCl}{ }_{4} \cdot 3 \mathrm{H}_{2} \mathrm{O}$, and $100 \mu \mathrm{L}$ of $10 \mathrm{mM} \mathrm{H}_{2} \mathrm{PdCl}_{4}$ was added to a $30 \mathrm{~mL}$ reaction vial. To introduce kinetic control, $2.0 \mathrm{~mL}$ of $\mathrm{HCl}$ was added to the growth solution/ The solutions were gently inverted to mix and $1.5 \mathrm{~mL}$ of 
freshly prepared $100 \mathrm{mM}$ L-AA was added. To this solution, $500 \mu \mathrm{L}$ Au octopod dispersion was added. After the addition of the Au seeds, the reaction vial was inverted twice and placed in an oil bath at $25{ }^{\circ} \mathrm{C}$ for $24 \mathrm{~h}$. The stellated $\mathrm{Au} / \mathrm{Pd}$ nanostructures were collected by centrifugation (10000 $\mathrm{rpm} / 12000 \mathrm{~g}$ ) for $15 \mathrm{~min}$, removed from supernatant and dispersed in $3 \mathrm{~mL}$ of water. The complete experimental parameters for each figure are described in the table below.

To achieve $3^{\text {rd }}$ generation structures, the above procedure was repeated again but with $2^{\text {nd }}$ generation structures. Polyhedra-tipped crystals were achieved by introducing $50 \mathrm{mM} \mathrm{HCl}$ and the branched crystals were achieved by introducing $0 \mathrm{mM} \mathrm{HCl}$. Note that reactions were ran at $1 / 4^{\text {th }}$ the total volume above.

\begin{tabular}{cccccc} 
Figure & CTAB/CTAC & NaBr & HCl & Au $(\boldsymbol{\mu L})$ & Pd $(\boldsymbol{\mu L})$ \\
\hline Figure 1 G1 & CTAB & $0 \mathrm{mM}$ & $0 \mathrm{mM}$ & 50 & 100 \\
Figure 1 G2 & CTAB & $0 \mathrm{mM}$ & $50 \mathrm{mM}$ & 50 & 100 \\
Figure 1 G2 & CTAB & $0 \mathrm{mM}$ & $0 \mathrm{mM}$ & 50 & 100 \\
Figure 1 G3 & CTAB & $0 \mathrm{mM}$ & $50 \mathrm{mM}$ & 50 & 100 \\
Figure 1 G3 & CTAB & $0 \mathrm{mM}$ & $0 \mathrm{mM}$ & 50 & 100 \\
Figure 1 G3 & CTAB & $0 \mathrm{mM}$ & $50 \mathrm{mM}$ & 50 & 100 \\
Figure 1 G3 & CTAB & $0 \mathrm{mM}$ & $0 \mathrm{mM}$ & 50 & 100 \\
Figure 2 A & CTAB & $0 \mathrm{mM}$ & $0 \mathrm{mM}$ & 50 & 100 \\
Figure 2 F & CTAB & $0 \mathrm{mM}$ & $50 \mathrm{mM}$ & 50 & 100 \\
\hline
\end{tabular}




\begin{tabular}{|c|c|c|c|c|c|}
\hline Figure & СТАВ/СТАС & $\mathrm{NaBr}$ & $\mathrm{HCl}$ & $A u(\mu L)$ & $\operatorname{Pd}(\mu \mathrm{L})$ \\
\hline Figure $3 \mathrm{~A}$ & CTAB & $0 \mathrm{mM}$ & $0 \mathrm{mM}$ & 50 & 100 \\
\hline Figure $3 \mathrm{~B}$ & CTAB & $0 \mathrm{mM}$ & $0 \mathrm{mM}$ & 50 & 100 \\
\hline Figure 5 A1 & CTAC & $400 \mathrm{mM}$ & $0 \mathrm{mM}$ & 50 & 100 \\
\hline Figure 5 A2 & CTAC & $350 \mathrm{mM}$ & $0 \mathrm{mM}$ & 50 & 100 \\
\hline Figure 5 A3 & CTAC & $300 \mathrm{mM}$ & $0 \mathrm{mM}$ & 50 & 100 \\
\hline Figure 5 A4 & CTAC & $150 \mathrm{mM}$ & $0 \mathrm{mM}$ & 50 & 100 \\
\hline Figure 5 B1 & CTAC & $400 \mathrm{mM}$ & $12.5 \mathrm{mM}$ & 50 & 100 \\
\hline Figure 5 B2 & CTAC & $350 \mathrm{mM}$ & $12.5 \mathrm{mM}$ & 50 & 100 \\
\hline Figure 5 B3 & CTAC & $300 \mathrm{mM}$ & $12.5 \mathrm{mM}$ & 50 & 100 \\
\hline Figure 5 B4 & CTAC & $150 \mathrm{mM}$ & $12.5 \mathrm{mM}$ & 50 & 100 \\
\hline Figure $5 \mathrm{C} 1$ & CTAC & $400 \mathrm{mM}$ & $25 \mathrm{mM}$ & 50 & 100 \\
\hline Figure 5 C2 & CTAC & $350 \mathrm{mM}$ & $25 \mathrm{mM}$ & 50 & 100 \\
\hline Figure 5 C3 & CTAC & $300 \mathrm{mM}$ & $25 \mathrm{mM}$ & 50 & 100 \\
\hline Figure 5 C4 & CTAC & $150 \mathrm{mM}$ & $25 \mathrm{mM}$ & 50 & 100 \\
\hline Figure 5 D1 & CTAC & $400 \mathrm{mM}$ & $50 \mathrm{mM}$ & 50 & 100 \\
\hline Figure 5 D2 & CTAC & $350 \mathrm{mM}$ & $50 \mathrm{mM}$ & 50 & 100 \\
\hline
\end{tabular}




\begin{tabular}{cccccc} 
Figure & CTAB/CTAC & NaBr & HCl & Au $(\boldsymbol{\mu L})$ & Pd $(\boldsymbol{\mu L})$ \\
\hline Figure 5 C3 & CTAC & $300 \mathrm{mM}$ & $50 \mathrm{mM}$ & 50 & 100 \\
Figure 5 C4 & CTAC & $150 \mathrm{mM}$ & $50 \mathrm{mM}$ & 50 & 100 \\
Figure 5 A1 & CTAC & $400 \mathrm{mM}$ & $0 \mathrm{mM}$ & 50 & 100 \\
Figure 5 A2 & CTAC & $350 \mathrm{mM}$ & $0 \mathrm{mM}$ & 50 & 100 \\
Figure S7 A & CTAB & $0 \mathrm{mM}$ & $0 \mathrm{mM}$ & 50 & 100 \\
Figure S7 B & CTAB & $0 \mathrm{mM}$ & $50 \mathrm{mM}$ & 50 & 100 \\
Figure S7 C & CTAB & $0 \mathrm{mM}$ & $100 \mathrm{mM}$ & 50 & 100 \\
\hline
\end{tabular}

For Supplemental Figure S13, the influence of halide concentration was explored by increasing the volume of CTAB added. Using the same conditions above, the volume of CTAB was systematically increases from $2.0 \mathrm{~mL}$ to $5.0 \mathrm{~mL}$. The details are summarized in the table below.

\begin{tabular}{ccc} 
Figure S13 & Volume of CTAB & HCl \\
\hline A1 & $2.0 \mathrm{~mL}$ & $0 \mathrm{mM}$ \\
A2 & $3.0 \mathrm{~mL}$ & $0 \mathrm{mM}$ \\
A3 & $4.0 \mathrm{~mL}$ & $0 \mathrm{mM}$ \\
A4 & $5.0 \mathrm{~mL}$ & $0 \mathrm{mM}$ \\
\hline
\end{tabular}




\begin{tabular}{ccc} 
Figure S13 & Volume of CTAB & HCl \\
\hline B1 & $2.0 \mathrm{~mL}$ & $12.5 \mathrm{mM}$ \\
B2 & $3.0 \mathrm{~mL}$ & $12.5 \mathrm{mM}$ \\
B3 & $4.0 \mathrm{~mL}$ & $12.5 \mathrm{mM}$ \\
B4 & $5.0 \mathrm{~mL}$ & $12.5 \mathrm{mM}$ \\
C1 & $2.0 \mathrm{~mL}$ & $25 \mathrm{mM}$ \\
C2 & $3.0 \mathrm{~mL}$ & $25 \mathrm{mM}$ \\
C3 & $4.0 \mathrm{~mL}$ & $25 \mathrm{mM}$ \\
C4 & $5.0 \mathrm{~mL}$ & $25 \mathrm{mM}$ \\
D1 & $2.0 \mathrm{~mL}$ & $50 \mathrm{mM}$ \\
D2 & $3.0 \mathrm{~mL}$ & $50 \mathrm{mM}$ \\
D3 & $4.0 \mathrm{~mL}$ & $50 \mathrm{mM}$ \\
D4 & $5.0 \mathrm{~mL}$ & $50 \mathrm{mM}$ \\
\hline
\end{tabular}

Troubleshooting:

1. Similarly to the octopods, the reaction can be successfully scaled up to $10 \mathrm{x}$ the reported volumes. Furthermore, the reaction can be scaled down to $1 / 5^{\text {th }}$ the original volume.

2. Hierarchical crystals will crash out over time. Vortex or vigorous shaking is required to disperse samples. 
3. The quality of the hierarchical crystal is strictly dependent on the quality of the seed. Make sure the initial structures are of high quality.

\section{Tuning Composition with Kinetically Controlled SMCR}

As discussed above, the composition of a hierarchical crystals can be tuned by changing the ratio of $\mathrm{Au}$ and $\mathrm{Pd}$ salts in the growth solution. To achieve this, a growth solution containing $5.35 \mathrm{~mL}$ of $\mathrm{H}_{2} \mathrm{O}, 0.50 \mathrm{~mL}$ of $200 \mathrm{mM} \mathrm{CTAB}, 250 \mu \mathrm{L}$ of $10 \mathrm{mM} \mathrm{HAuCl}_{4} \cdot 3 \mathrm{H}_{2} \mathrm{O}$, and $250 \mu \mathrm{L}$ of $\mathrm{H}_{2} \mathrm{PdCl}_{4}$ was added to a $30 \mathrm{~mL}$ reaction vial. To introduce kinetic control, $0.50 \mathrm{~mL}$ of $\mathrm{HCl}$ was added to the growth solution. The solutions were gently inverted to mix and $375 \mu \mathrm{L}$ of freshly prepared $100 \mathrm{mM} \mathrm{L-AA}$ was added. To this solution, $400 \mu \mathrm{L}$ octopod dispersion was added. After the addition of the Au seeds, the reaction vial was inverted twice and placed in an oil bath at 25 ${ }^{\circ} \mathrm{C}$ for $3 \mathrm{~h}$. The stellated $\mathrm{Au} / \mathrm{Pd}$ nanostructures were collected by centrifugation (10000 $\mathrm{rpm} / 12000 \mathrm{~g}$ ) for $15 \mathrm{~min}$, removed from supernatant and dispersed in $3 \mathrm{~mL}$ of water. The experimental parameters for each figure are described in the table below.

\begin{tabular}{cccc} 
Figure & HCl & Pd (mM) & $\begin{array}{c}\text { Au:Pd } \\
\text { Ratio }\end{array}$ \\
\hline Figure 6 A1 & $0 \mathrm{mM}$ & 0.1 & $100: 1$ \\
Figure 6 A2 & $0 \mathrm{mM}$ & 0.2 & $50: 1$ \\
Figure 6 A3 & $0 \mathrm{mM}$ & 1.0 & $10: 1$ \\
Figure 6 A4 & $0 \mathrm{mM}$ & 2.0 & $5: 1$ \\
\hline
\end{tabular}




\begin{tabular}{|c|c|c|c|}
\hline Figure & $\mathrm{HCl}$ & $P d(m M)$ & $\begin{array}{c}\text { Au:Pd } \\
\text { Ratio }\end{array}$ \\
\hline Figure 6 B1 & $12.5 \mathrm{mM}$ & 0.1 & $100: 1$ \\
\hline Figure 6 B2 & $12.5 \mathrm{mM}$ & 0.2 & $50: 1$ \\
\hline Figure 6 B3 & $12.5 \mathrm{mM}$ & 1.0 & $10: 1$ \\
\hline Figure 6 B4 & $12.5 \mathrm{mM}$ & 2.0 & $5: 1$ \\
\hline Figure $6 \mathrm{C} 1$ & $25 \mathrm{mM}$ & 0.1 & $100: 1$ \\
\hline Figure $6 \mathrm{C} 2$ & $25 \mathrm{mM}$ & 0.2 & $50: 1$ \\
\hline Figure $6 \mathrm{C} 3$ & $25 \mathrm{mM}$ & 1.0 & 10:1 \\
\hline Figure 6 C4 & $25 \mathrm{mM}$ & 2.0 & $5: 1$ \\
\hline Figure 6 D1 & $50 \mathrm{mM}$ & 0.1 & 100:1 \\
\hline Figure 6 D2 & $50 \mathrm{mM}$ & 0.2 & $50: 1$ \\
\hline Figure 6 D3 & $50 \mathrm{mM}$ & 1.0 & $10: 1$ \\
\hline Figure 6 D4 & $50 \mathrm{mM}$ & 2.0 & $5: 1$ \\
\hline
\end{tabular}

To achieve trimetallic hierarchical crystals, a growth solution consisting of $5.0 \mathrm{~mL}$ of water, $500 \mu \mathrm{L}$ of $200 \mathrm{mM} \mathrm{CTAB}$, some volume of metal precursor, and $500 \mu \mathrm{L}$ of $50 \mathrm{mM} \mathrm{HCl}$ was prepared in glass vial. $10 \mathrm{mM} \mathrm{AgNO}, 10 \mathrm{mM} \mathrm{H}_{2} \mathrm{PdCl}_{4}$, and $10 \mathrm{mM} \mathrm{HAuCl}_{4}$ were used as metal precursors. The metal precursors were reduced by $375 \mu \mathrm{L}$ of $100 \mathrm{mM}$ L-AA in the presence of $350 \mu \mathrm{L}$ of $\mathrm{Au} / \mathrm{Pd}$ octopodal seeds. The reaction was allowed to react for 24 hours and collected 
via centrifugation. The volumes of metal precursors were used to generate the multimetallic hierarchical crystals are listed in the following table.

\begin{tabular}{cccc} 
Sample & $\mathbf{A g N O}_{3}(\mu \mathbf{L})$ & $\mathbf{H}_{2} \mathbf{P d C l}_{4}(\mu \mathbf{L})$ & $\mathbf{H A u C l}_{4}(\mu \mathbf{L})$ \\
\hline Figure S14 A & 150 & 0 & 0 \\
Figure S14 B & 120 & 0 & 30 \\
Figure S14 C & 120 & 30 & 0 \\
Figure S14 D & 30 & 0 & 120 \\
Figure S14 E & 50 & 50 & 50 \\
Figure S14 F & 30 & 120 & 0 \\
Figure S14 G & 0 & 0 & 150 \\
Figure S14 H & 0 & 30 & 120 \\
Figure S14 I & 0 & 120 & 30 \\
Figure S14 J & 0 & 150 & 0 \\
\hline
\end{tabular}

Synthesis of Hierarchical Crystals with Quasi-D5h Symmetry

As described in previous work, 10-branched nanocrystals with $\mathrm{D}_{5 h}$ symmetry were synthesized by performing SMCR onto preformed decahedral seeds with minor modifications. ${ }^{4,5}$ A growth solution containing $4.26 \mathrm{~mL}$ of $\mathrm{H}_{2} \mathrm{O}, 0.5 \mathrm{~mL}$ of $200 \mathrm{mM} \mathrm{CTAC}, 10 \mu \mathrm{L}$ of $100 \mathrm{mM}$ $\mathrm{HAuCl}_{4}$, and $20 \mu \mathrm{L}$ of $10 \mathrm{mM} \mathrm{H}_{2} \mathrm{PdCl}_{4}$, and $500 \mu \mathrm{L}$ of $\mathrm{NaBr}$ was prepared in a scintillation vial. 
Next, a volume of $\mathrm{HCl}(50 \mathrm{mM})$ was added to the reaction. After this, $300 \mu \mathrm{L} \mathrm{mL}$ of freshly prepared $100 \mathrm{mM}$ L-AA was added, and the growth solution was vigorously shaken. Last, $125 \mu \mathrm{L}$ of 10-branched decahedral seeds were added and the reaction was placed in an oil bath at $25^{\circ} \mathrm{C}$ overnight. The hierarchical crystals were collected by centrifugation $(10,000 \mathrm{rpm} / 12,000 \mathrm{~g})$ after 15 minutes and diluted with $1 \mathrm{~mL}$ of water. The concentration of $\mathrm{NaBr}$ and volume of $\mathrm{HCl}$ added to each solution is reported in the table below.

\begin{tabular}{ccc} 
Sample & [NaBr] $(\mathbf{m M})$ & Vol. HCl $(\mu \mathbf{L})$ \\
\hline Figure S16 A1 & 50 & 0 \\
$\begin{array}{c}\text { Figure S16 A2 } \\
\text { Figure 7C-G }\end{array}$ & 70 & 0 \\
Figure S16 A3 & 120 & 0 \\
Figure S16 A4 & 160 & 0 \\
Figure S16 B1 & 50 & 100 \\
Figure S16 B2 & 70 & 100 \\
Figure S16 B3 & 120 & 100 \\
Figure S16 B4 & 160 & 100 \\
Figure S16 C1 & 50 & 200 \\
Figure S16 C2 & 70 & 200 \\
Figure S16 C3 & 120 & 200 \\
\hline
\end{tabular}




\begin{tabular}{ccc} 
Sample & {$[\mathbf{N a B r}](\mathbf{m M})$} & Vol. HCl $(\boldsymbol{\mu L})$ \\
\hline Figure S16 C4 & 160 & 200 \\
Figure S16 D1 & 50 & 300 \\
Figure S16 D2 & 70 & 300 \\
Figure S16 D3 & 120 & 300 \\
$\begin{array}{c}\text { Figure S16 D4 } \\
\text { Figure 7H-L }\end{array}$ & 160 & 300 \\
\hline
\end{tabular}

\section{Sample Characterization}

Samples for scanning electron microscopy (SEM) were prepared by drop-casting a colloidal solution of nanocrystals onto a cut $\mathrm{Si}$ wafer. After the water evaporated, the Si wafers were cleaned with methanol several times to remove excess surfactant. SEM images were obtained with a FEI Quanta FEG 600 field-emission environmental SEM operating at $30 \mathrm{kV}$ with a spot size of 3. The SEM was interfaced to an Oxford AZtec detector for energy-dispersive X-ray spectroscopy (EDS); 3-5 full-coverage regions $(>1 \mu \mathrm{m} 3)$ were analyzed per sample. For tilt studies, SEM images were acquired on Zeiss Auriga 60 Focused Ion Beam-Scanning Electron Microscope operated at $30 \mathrm{kV}$ with a spot size of 3 . Images were collected when the stage was tilted at $0^{\circ}, 25^{\circ}$, and $50^{\circ}$.

Samples for analysis by scanning transmission electron microscopy (STEM) were prepared by washing a carbon-coated copper grid with chloroform to remove Formvar and then drop-casting a dilute nanoparticle solution onto the grid. Grids were then soaked in methanol for 24 hours. STEM images were obtained with a JEOL JEM 3200FS transmission electron microscope at 300 
$\mathrm{kV}$, equipped with a camera Gatan 4kx4k Ultrascan 4000. EDX spectra were measured with an Oxford AZtec dispersive X-ray system interfaced to the microscope, operating at $300 \mathrm{kV}$.

UV-vis-NIR spectra were collected on a Varian Cary 5000 UV-vis-NIR spectrometer at room temperature with a spectral range from 400-1300 nm. From a larger growth solution, $5 \mathrm{~mL}$ of aqueous colloidal solutions were dispensed in quartz cuvettes.

For ICP-MS analysis, supernatant and nanoparticles were separated by centrifugation $(10,000 \mathrm{rpm} / 12,000 \mathrm{~g})$ for $10 \mathrm{~min}$. Supernatant was diluted to the desired concentration with $2 \%$ nitric acid solution. To digest the nanocrystals, the solid precipitate was dispersed into $1 \mathrm{~mL}$ of nanopure water. Then, $2 \mathrm{~mL}$ of fresh Aqua Regia was added to digest the nanocrystals overnight. The samples were diluted until the concentration of nitric acid was $2 \%$ ( 17 additional $\mathrm{mL}$ of water). Then the samples were diluted to appropriate concentration using 2\% nitric acid (10:1 diluted aqua regia to $2 \%$ nitric solution). Samples were analyzed in conjunction with IU faculty at the Stable Isotope Research Facility using an Agilent 7700 quadrupole ICP-MS.

The $\mathrm{pH}$ of the solution was measure using a VWR SympHony B10P model $\mathrm{pH}$ meter. The $\mathrm{pH}$ probe was purchased from VWR and has a model number 89231-596. Fill solution for the $\mathrm{pH}$ meter is $3 \mathrm{M} \mathrm{KCl}$. The system was calibrated with standard ph buffers $4,7,10$ by BDH.

Powder X-ray diffraction patterns were collected on the PANalytical Empyrean instrument with $\mathrm{Cu} \mathrm{K} \alpha$ radiation and an $\mathrm{X}^{\prime}$ Celerator linear strip detector. 
Supporting Figures

a)

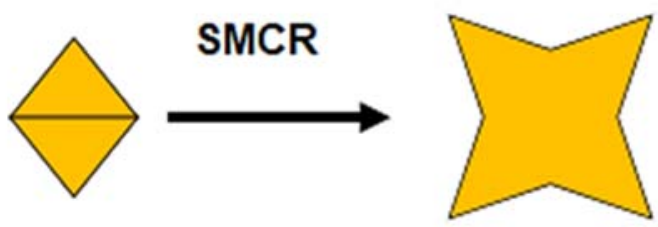

$\mathbf{G}_{0}$

b)

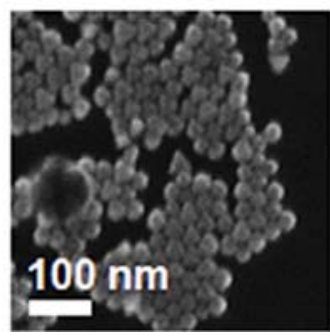

$G_{1}$

c)

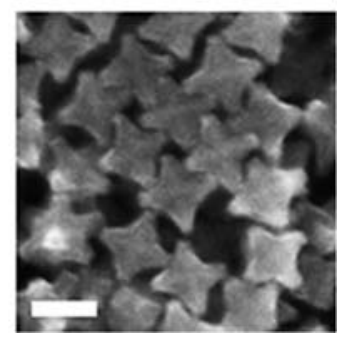

Figure S1. A) Schematic of performing seed-mediated co-reduction onto octahedra, resulting in the synthesis of 8-branched octopods. SEM images of b) octahedral and c) octopodal nanocrystals. All scale bars are $100 \mathrm{~nm}$.

Gen 1.

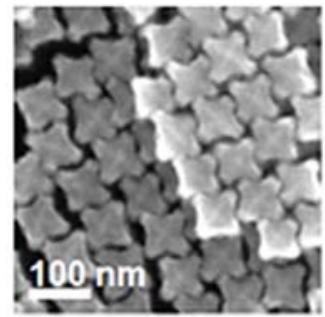

$90 \pm 6 \mathrm{~nm}$

Gen 2 .

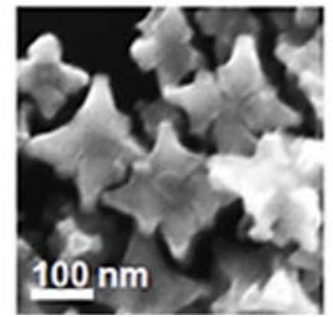

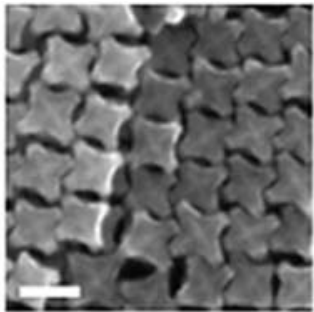

$104 \pm 6 \mathrm{~nm}$

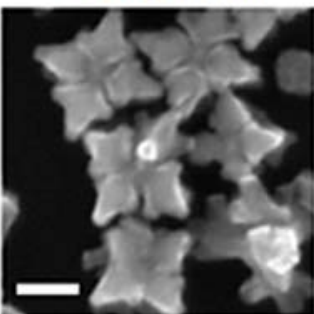

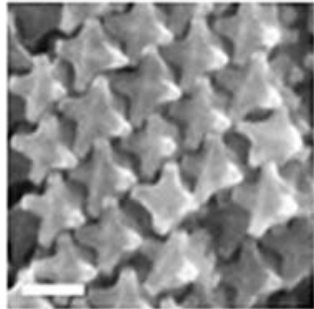

$118 \pm 6 \mathrm{~nm}$

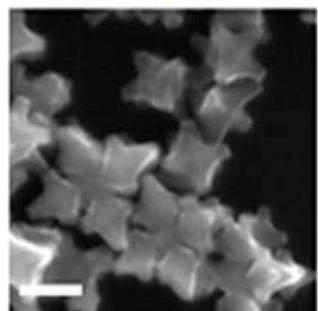

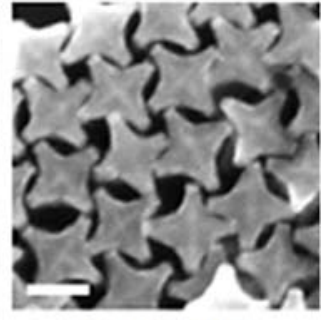

$150 \pm 6 \mathrm{~nm}$

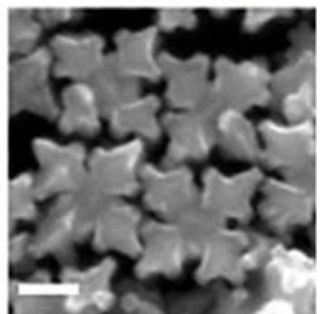

Figure S2. SEM images of different sized octopods used as $G_{1}$ seeds to generate $G_{2}$ hierarchically branched crystals shown directly below. The greater spatial separation between branches in the $G_{1}$ seeds makes the different features of the $G_{2}$ products more easily observed. All scale bars are 100 $\mathrm{nm}$. 


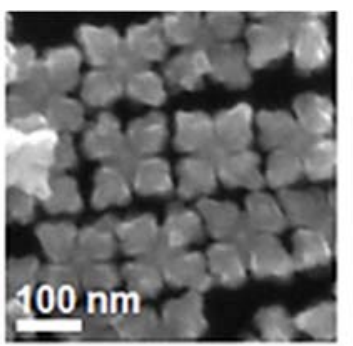

$800 \mu \mathrm{L}$

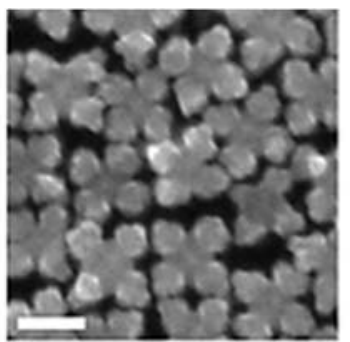

$1000 \mu \mathrm{L}$

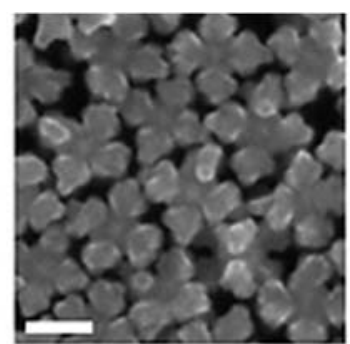

$1200 \mu \mathrm{L}$

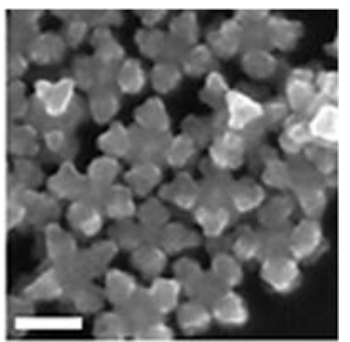

$1400 \mu \mathrm{L}$

Figure S3. SEM images of hierarchical structures achieved by increasing the amount of $G_{1}$ seeds in solution used to produce $G_{2}$ nanocrystals. All scale bars are $100 \mathrm{~nm}$.
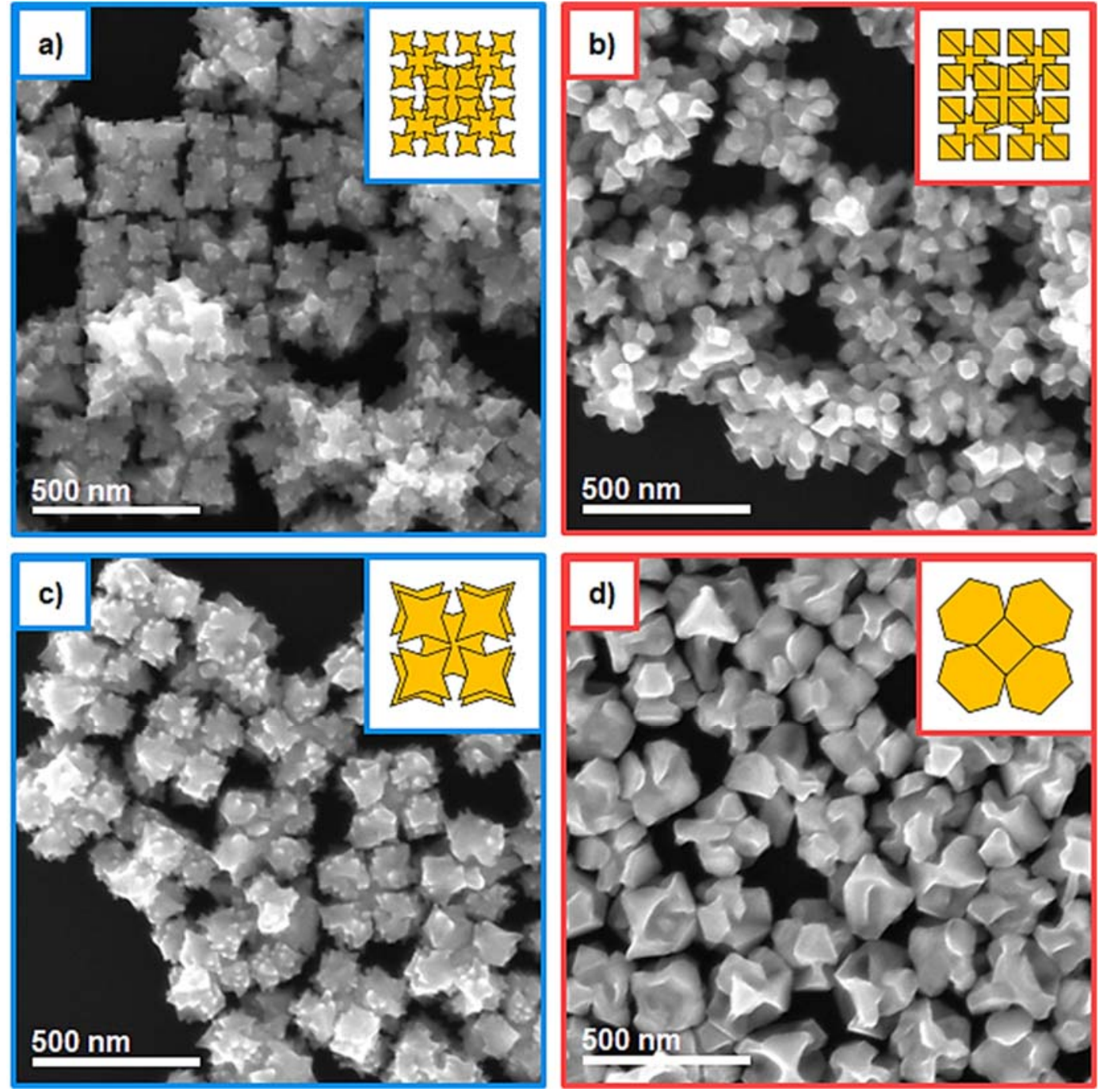

Figure S4. Scanning electron micrographs of hierarchical crystals with A) 128 branched, B) 32 polyhedra tipped, C) 160-branched, and D) mix of concave/convex crystals with respective model insets. The blue and red outlines indicate that samples were obtained under fast and slow deposition conditions 

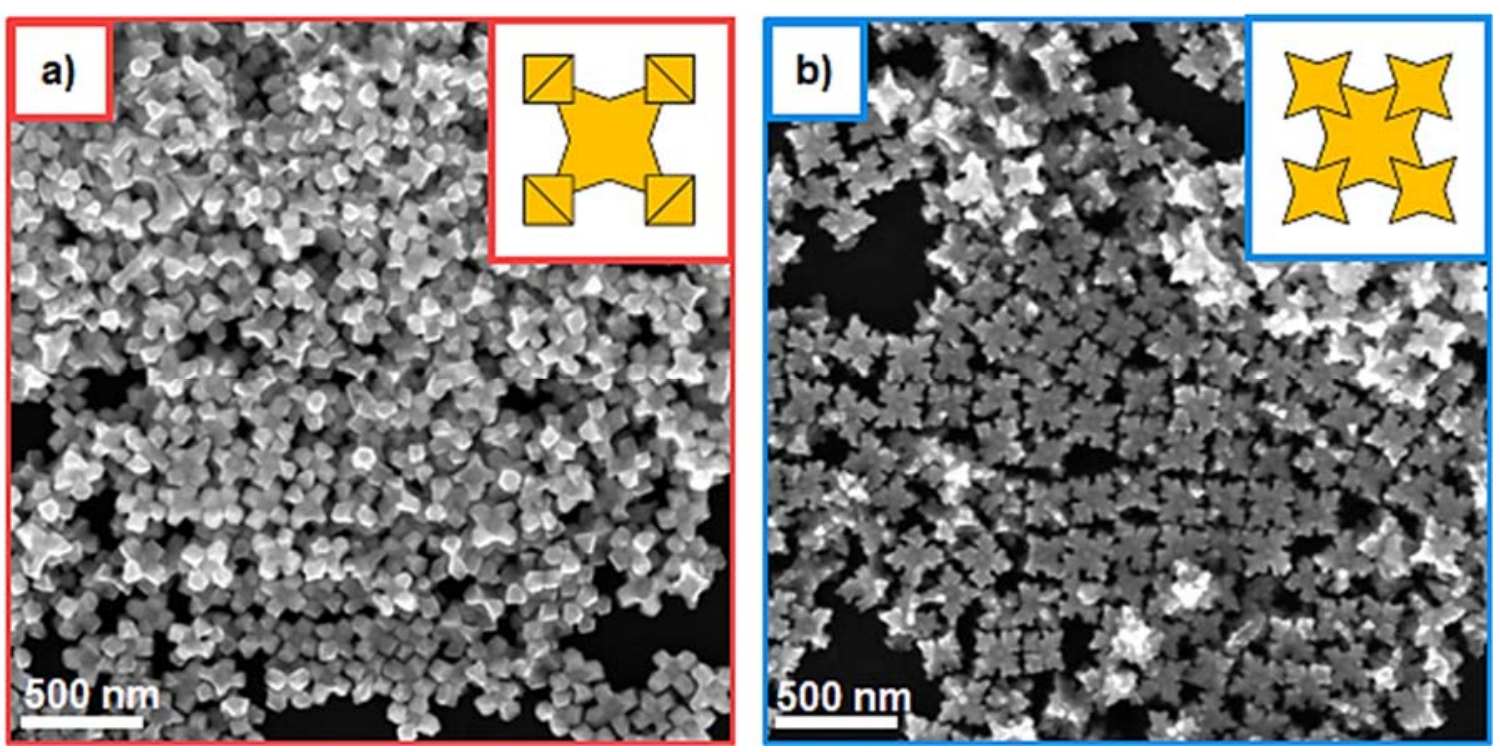

Figure S5. Scanning electron micrographs of $G_{2}$ A) polyhedra tipped hierarchical crystals and B) branched hierarchical crystals generated under fast (blue) and slow (red) kinetic conditions, respectively. Insets are 2-D conceptualization of products.

a)
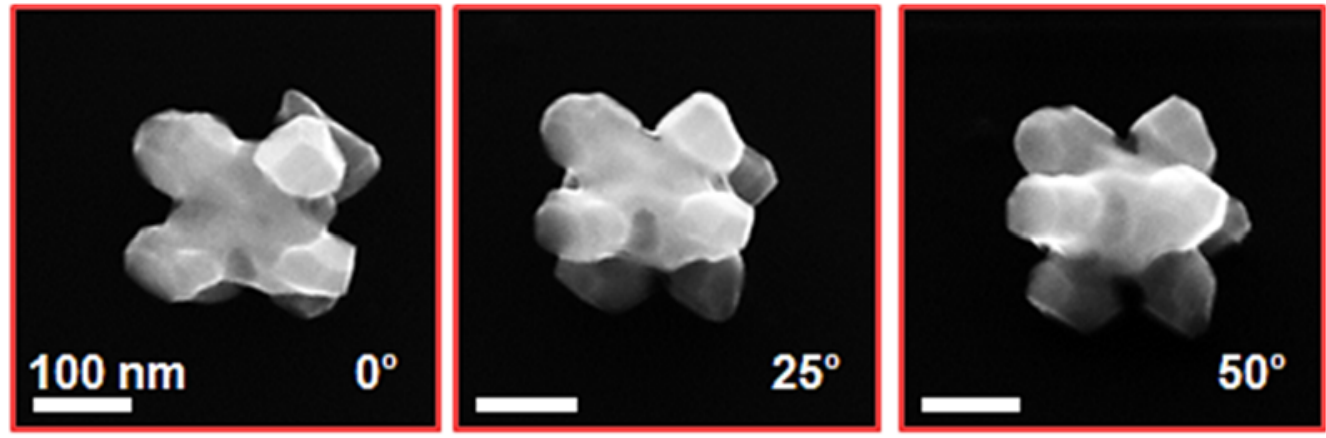

b)
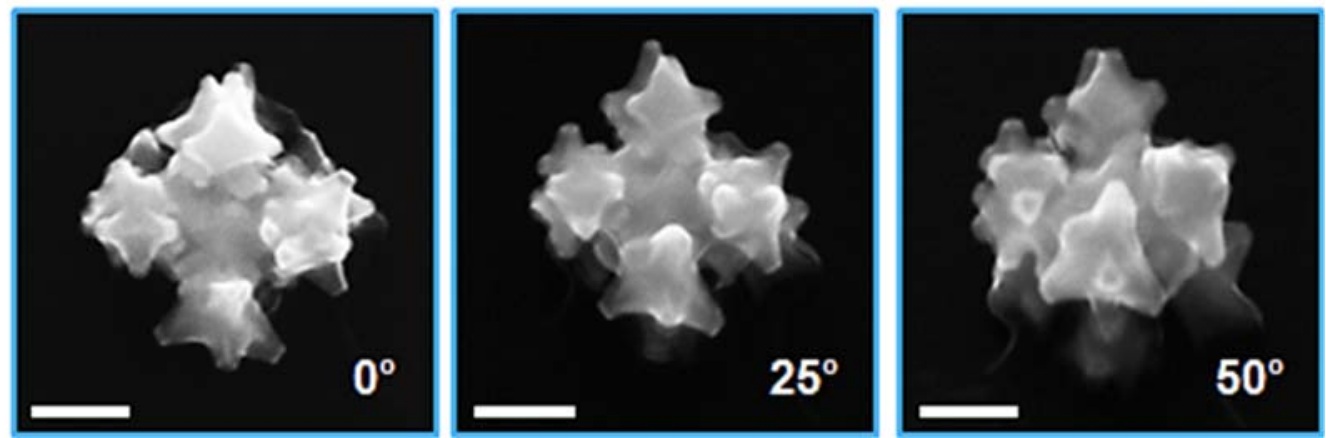

Figure S6. Tilt study of A) polyhedra tipped and B) "32-brancched" hierarchical nanocrystals at $0^{\circ}, 25^{\circ}$, and $50^{\circ}$. All scale bars are $100 \mathrm{~nm}$. The blue and red outlines indicate that samples were obtained under fast and slow deposition conditions. 


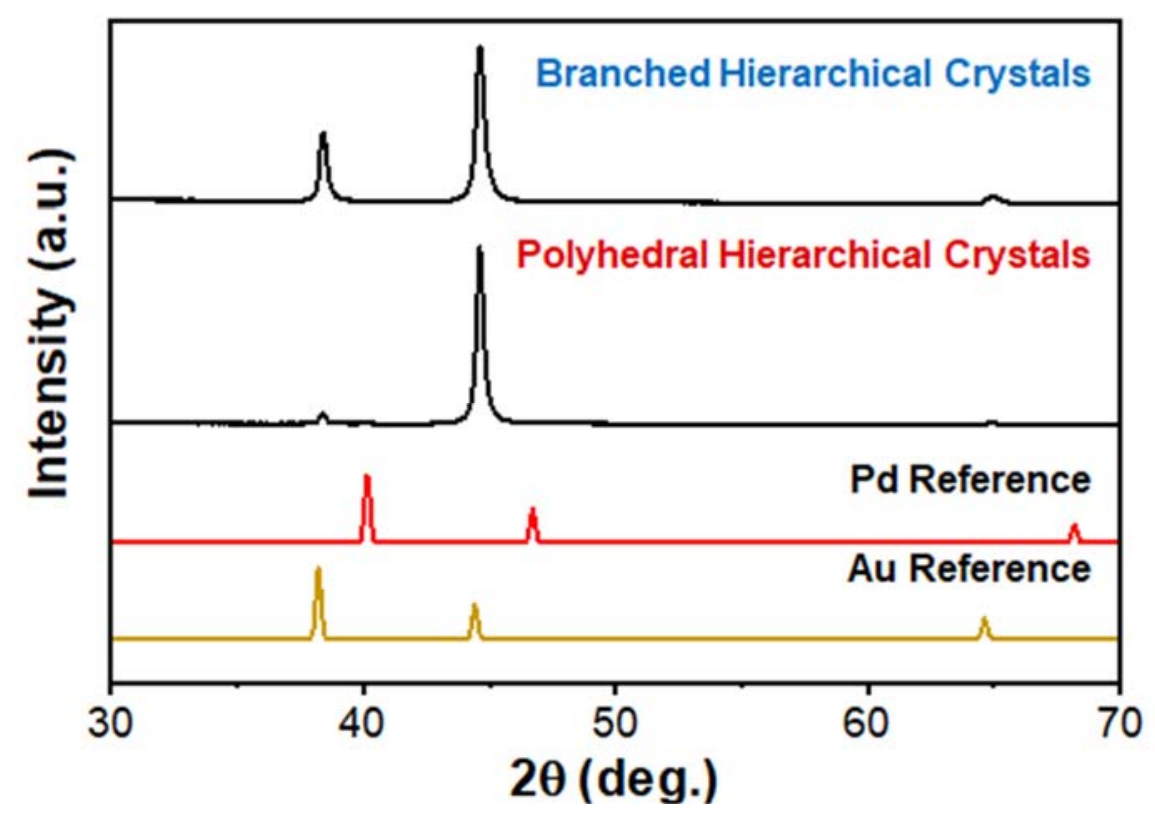

Figure S7. Powder X-ray diffraction patterns from hierarchical crystals with branched and polyhedral tipped hierarchical forms. Patterns are indicative of alloy formation. Yellow and red patterns correspond to $\mathrm{Au}$ and $\mathrm{Pd}$ references, respectively.
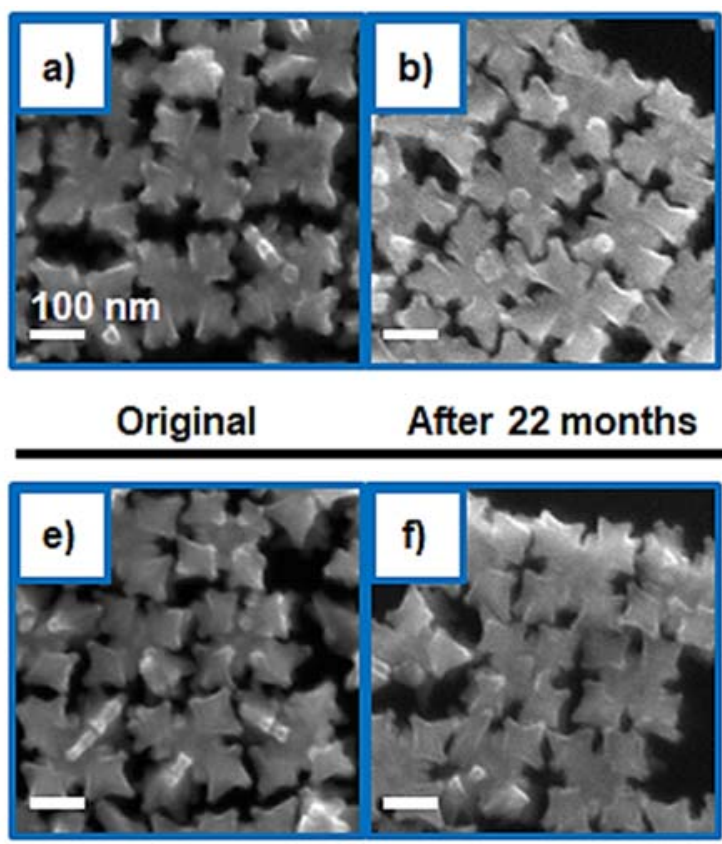

Original
After Boiling

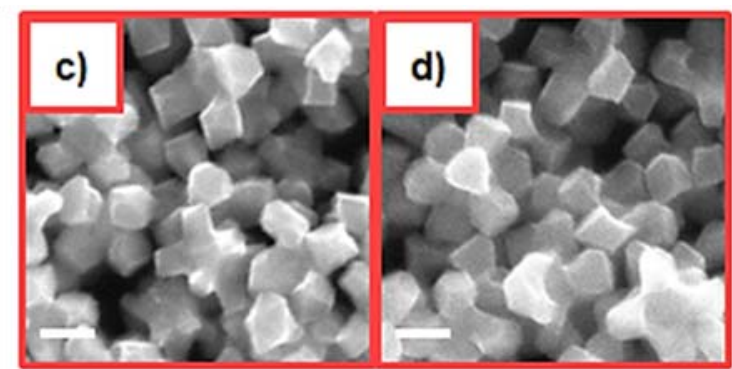

After 22 months

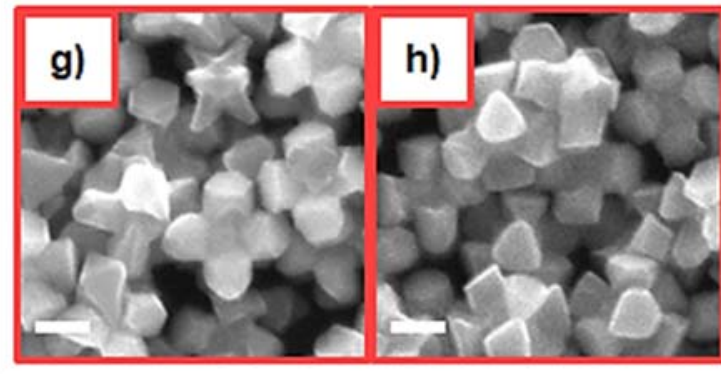

Original

After Boiling

Figure S8. Scanning electron micrographs of A,C,E,G) hierarchical crystals shortly after preparation and micrographs of the same crystals B,D) after being stored in aqueous solution for 22 months and F,H) after being boiled in aqueous solution for 1 hour. Overall, no significant structural changes are observed. All scale bars are $100 \mathrm{~nm}$. 


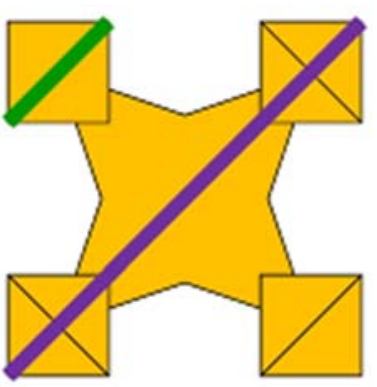

Tip Width

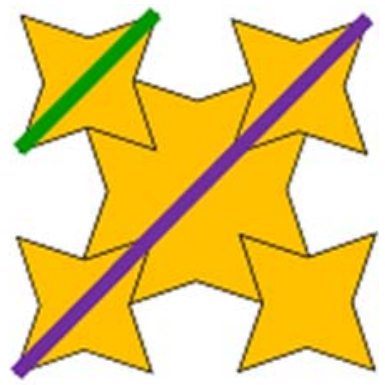

Tip-to-Tip

Figure S9. Schematic displaying measured dimension of hierarchical nanocrystals with the tip width represented in green and tip-to-tip length represented in purple.

a)

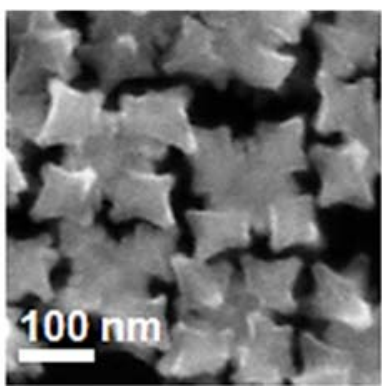

b)

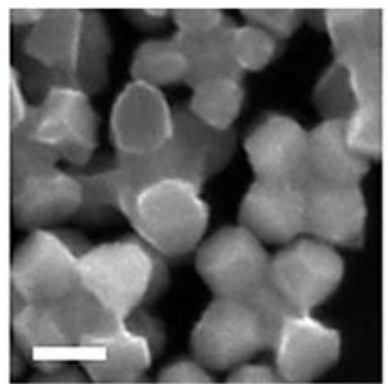

c)

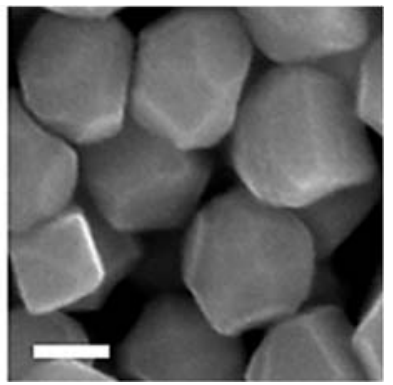

Figure S10. SEM images of crystals synthesized at a $\mathrm{pH}$ of A) 3.31, B) 2.38, and C) 1.57, respectively. All scale bars are $100 \mathrm{~nm}$. 


\begin{tabular}{llll} 
Time (seconds) & Tip-to-Tip (nm) & Tip Width $(\mathbf{n m})$ & [HCl] \\
\hline 0 & $189 \pm 9$ & $19 \pm 3$ & $0 \mathrm{mM}$ \\
10 & $187 \pm 9$ & $24 \pm 5$ & $0 \mathrm{mM}$ \\
30 & $197 \pm 10$ & $30 \pm 6$ & $0 \mathrm{mM}$ \\
120 & $198 \pm 11$ & $37 \pm 7$ & $0 \mathrm{mM}$ \\
180 & $209 \pm 10$ & $39 \pm 8$ & $0 \mathrm{mM}$ \\
300 & $223 \pm 12$ & $53 \pm 11$ & $0 \mathrm{mM}$ \\
1800 & $249 \pm 11$ & $82 \pm 10$ & $0 \mathrm{mM}$ \\
3600 & $251 \pm 18$ & $93 \pm 9$ & $0 \mathrm{mM}$ \\
0 & $190 \pm 8$ & $19 \pm 5$ & $50 \mathrm{mM}$ \\
10 & $189 \pm 11$ & $21 \pm 3$ & $50 \mathrm{mM}$ \\
30 & $190 \pm 12$ & $30 \pm 5$ & $50 \mathrm{mM}$ \\
120 & $191 \pm 10$ & $33 \pm 5$ & $50 \mathrm{mM}$ \\
180 & $196 \pm 12$ & $45 \pm 8$ & $50 \mathrm{mM}$ \\
300 & $200 \pm 13$ & $52 \pm 10$ & $50 \mathrm{mM}$ \\
1800 & $222 \pm 18$ & $68 \pm 8$ & $50 \mathrm{mM}$ \\
3600 & $245 \pm 15$ & $81 \pm 10$ & $50 \mathrm{mM}$ \\
\hline
\end{tabular}

Table S1. Summarization of structural characteristics at different time points. 

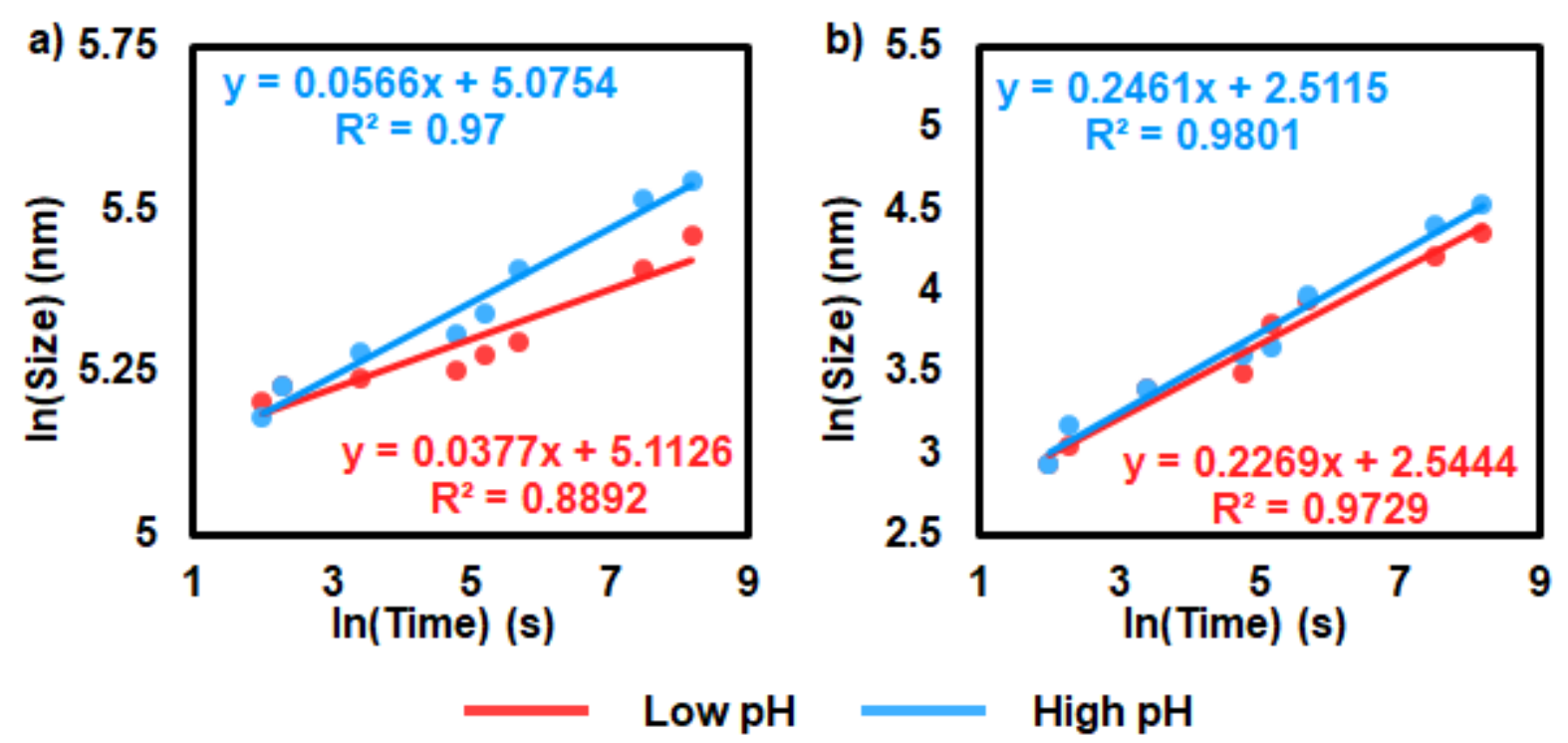

\section{High pH}

Figure S11. Plots of the natural log of size compared to the natural log of time are presented for A) tip-to-tip and B) tip width measurements. Reactions were performed under fast (blue) and slow (red) deposition kinetics

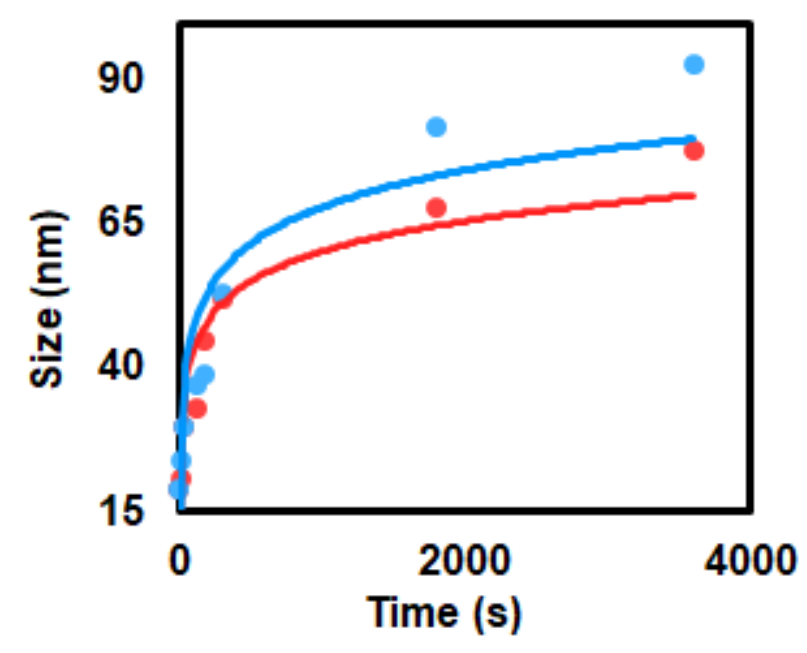

Figure S12. Graph of hierarchical nanocrystal size as a function of time of the tip width for reactions performed under fast (blue) and slow (red) deposition kinetics. 

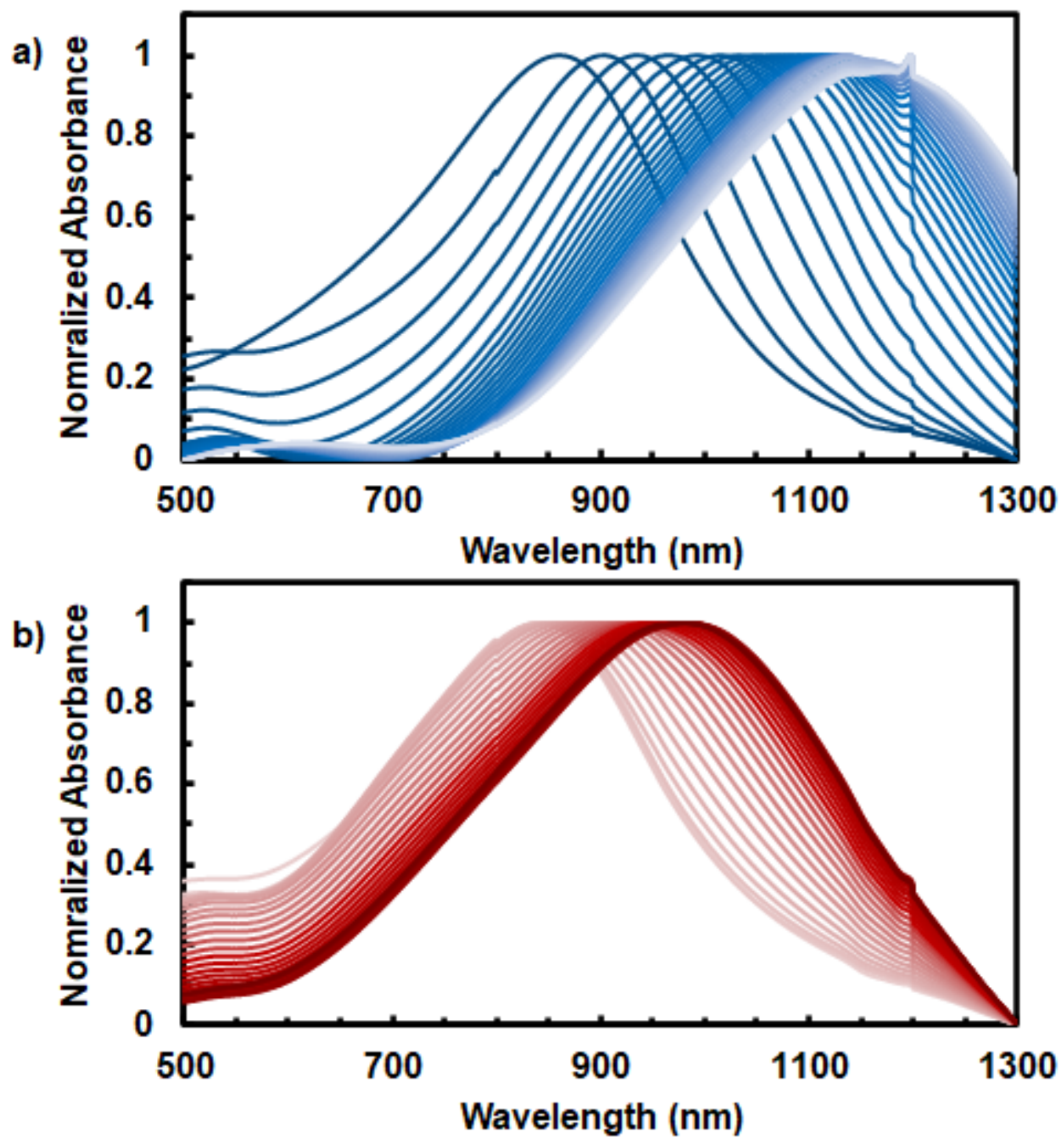

Figure S13. Normalized UV-Visible-Near Infrared spectra of hierarchical nanocrystals acquired every 158 s over a period of 4500 seconds. Spectra in A and B are acquired under fast (blue) and slow (red) deposition conditions, respectively. A gradual red-shift in the max absorbance is observed as time progresses. Note the artifact observed around $1200 \mathrm{~nm}$ is due to instrumental noise. 


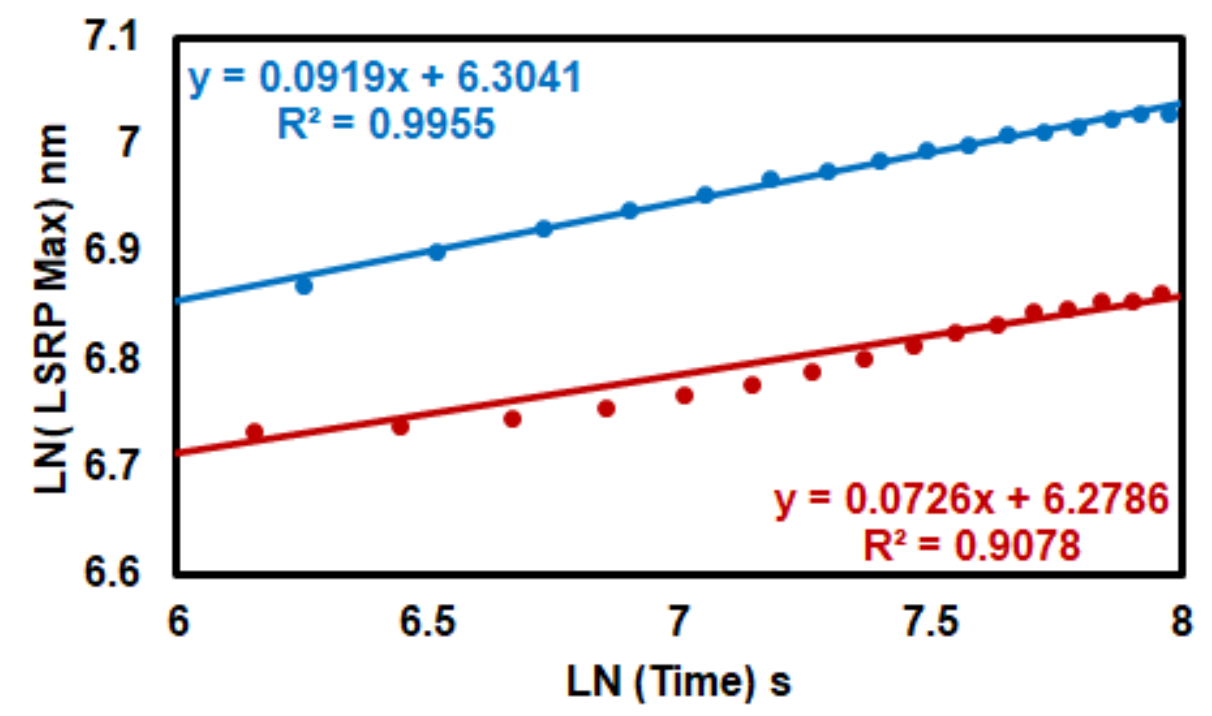

Figure S14. Plots of the natural log of LSPR Max of hierarchical crystals compared to the natural $\log$ of time are presented for fast deposition (blue) and slow deposition (red) conditions.

\begin{tabular}{cccc} 
Measurement & $\boldsymbol{v}_{\text {dep }}$ & Regression Analysis & $\mathbf{R}^{\mathbf{2}}$ \\
\hline Size (Tip-to-Tip), nm & Fast & $\mathrm{LN}(\mathrm{y})=0.057 \mathrm{LN}(\mathrm{x})+5.1$ & 0.97 \\
Size (Tip-to-Tip), nm & Slow & $\mathrm{LN}(\mathrm{y})=0.038 \mathrm{LN}(\mathrm{x})+5.1$ & 0.98 \\
Size (Tip Width), nm & Fast & $\mathrm{LN}(\mathrm{y})=0.246 \mathrm{LN}(\mathrm{x})+2.5$ & 0.98 \\
Size (Tip Width), nm & Slow & $\mathrm{LN}(\mathrm{y})=0.227 \mathrm{LN}(\mathrm{x})+2.5$ & 0.97 \\
LSPR Max, nm & Fast & $\mathrm{LN}(\mathrm{y})=0.912 \mathrm{LN}(\mathrm{x})+6.3$ & 0.99 \\
LSPR Max, nm & Slow & $\mathrm{LN}(\mathrm{y})=0.073 \mathrm{LN}(\mathrm{x})+6.3$ & 0.91 \\
[Au], $\mu \mathrm{M}$ & Fast & $\mathrm{LN}[\mathrm{Au}]=-0.000844 \mathrm{x}+3.3$ & 0.99 \\
[Au], $\mu \mathrm{M}$ & Slow & $\mathrm{LN}[\mathrm{Au}]=-0.00071 \mathrm{x}+3.3$ & 0.99 \\
[Pd], $\mu \mathrm{M}$ & Fast & $\mathrm{LN}[\mathrm{Pd}]=-0.00021 \mathrm{x}+1.4$ & 0.96 \\
[Pd], $\mu \mathrm{M}$ & Slow & $\mathrm{LN}[\mathrm{Pd}]=-0.00016 \mathrm{x}+1.5$ & 0.95 \\
\hline
\end{tabular}

Table S2. Sum of regression analysis for the time study analyzing the size, LSPR peak, and concentration of $\mathrm{Au} / \mathrm{Pd}$ by SEM, UV-Vis-NIR spectroscopy, and inductively coupled plasma couple - mass spectroscopy, respectively. 


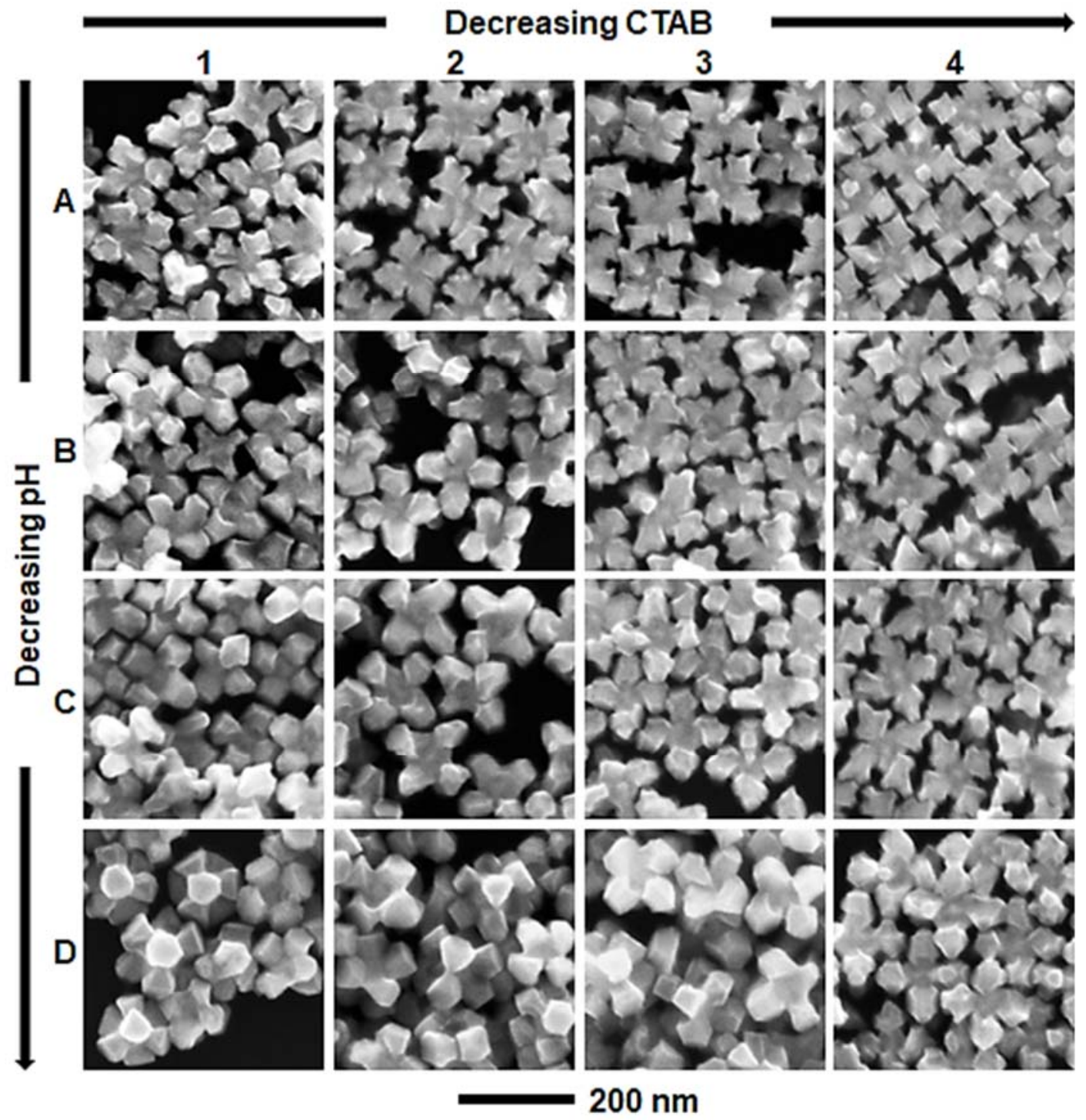

Figure S15. SEM images of hierarchical nanocrystals obtained by increasing $\mathrm{HCl}$ and increasing the concentration of CTAB. The concentration of added $\mathrm{HCl}$ in rows A, B, C, D was $0 \mathrm{mM}, 12.5$ $\mathrm{mM}, 25 \mathrm{mM}$, and $50 \mathrm{mM}$. The volume of CTAB added to each solution was $2.0 \mathrm{~mL}, 3.0 \mathrm{~mL}, 4.0$ $\mathrm{mL}$, and $5.0 \mathrm{~mL}$ for Columns 1,2,3, and 4, respectively. 


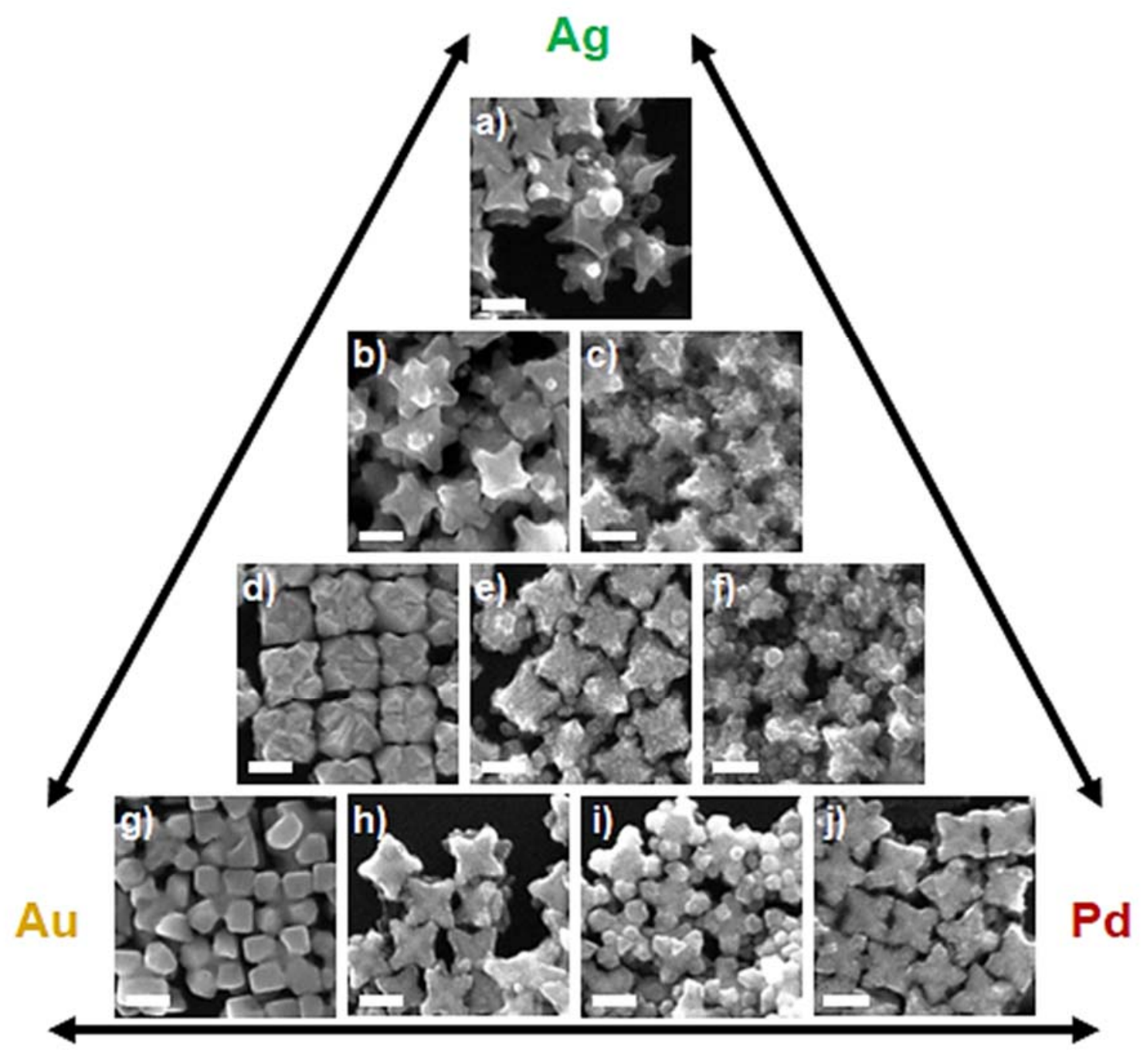

Figure S16. SEM images of trimetallic hierarchical nanocrystals synthesized with different ratio of $\mathrm{Au}, \mathrm{Ag}$, and $\mathrm{Pd}$. From the top and going to left to right, $\mathrm{Au}: \mathrm{Pd}: \mathrm{Ag}$ were deposited in $\mathrm{A})$ 0:0:1, B) $1: 0: 5$, C) $0: 1: 5$, D) 5:0:1, E) 1:1:1, F) 0:5:1, G) 1:0:0, H) 5:1:0, I) 1:5:0, and J) 0:1:0 onto Au/Pd octopods. Note, these experiments will require a full individual study to understand the principles governing hierarchical nanocrystal growth for each system. All scale bars are $100 \mathrm{~nm}$. 
a)
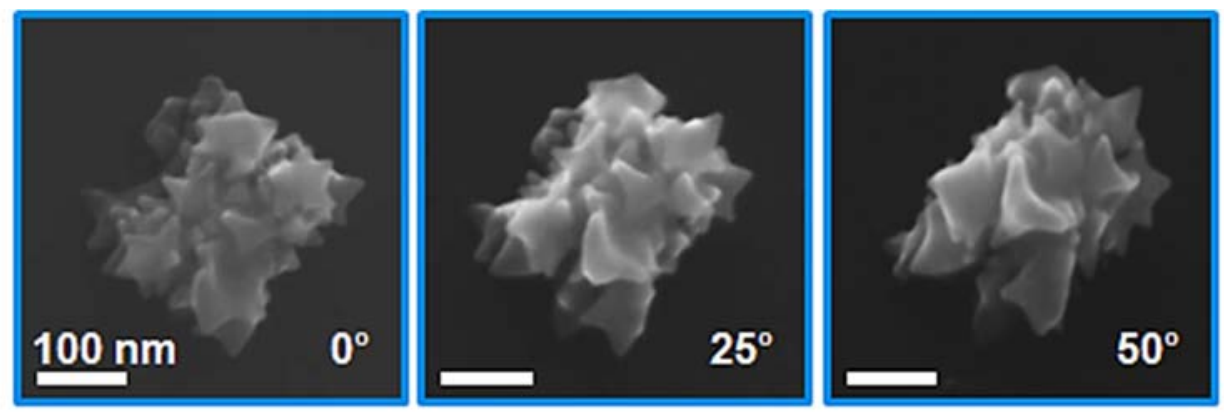

b)
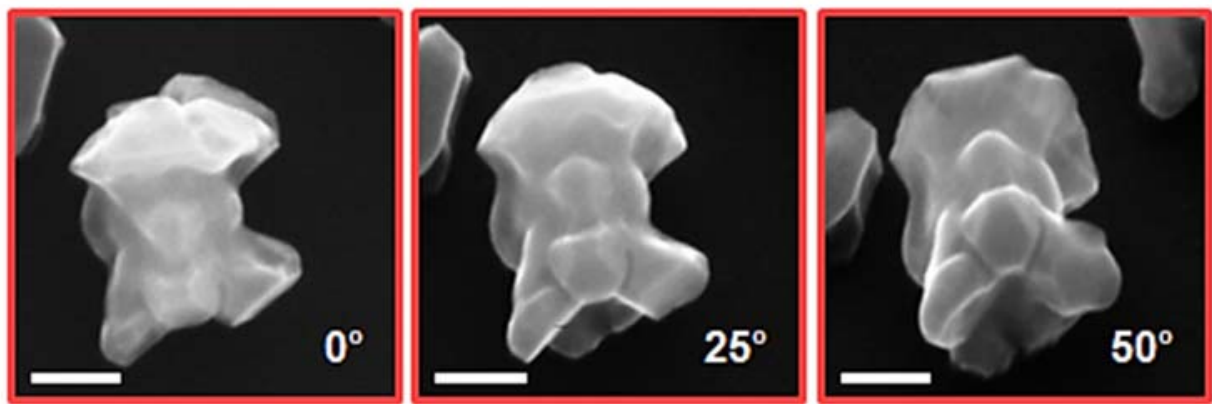

Figure S17. SEM tilt study of A) polyhedral tipped and B) "40-branched" quasi- $D_{5 h}$ hierarchical nanocrystals at $0^{\circ}, 25^{\circ}$, and $50^{\circ}$. The blue and red outlines indicate that samples were obtained under fast and slow deposition conditions. All scale bars are $100 \mathrm{~nm}$. 


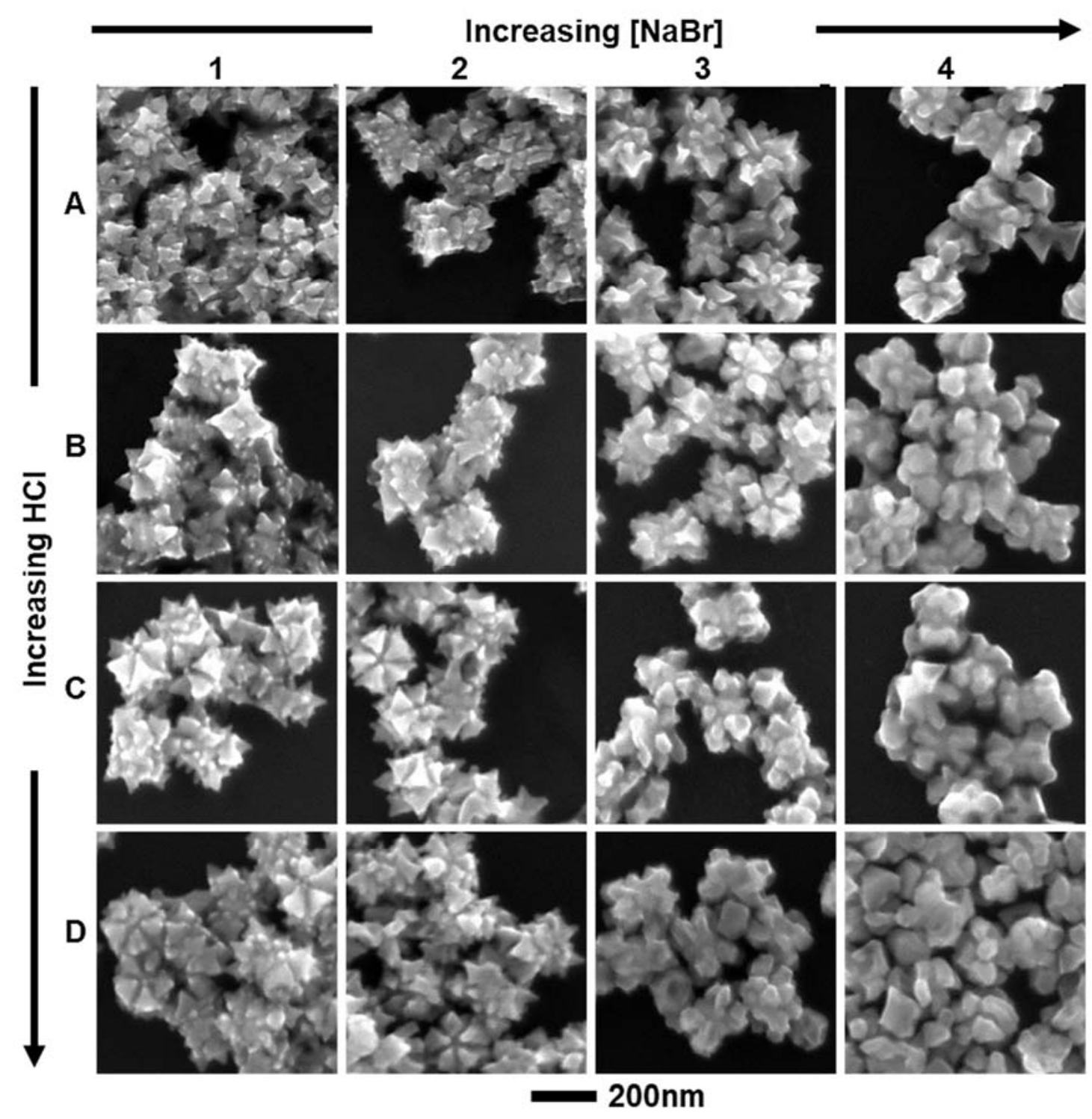

Figure S18. SEM images of hierarchical nanocrystals grown from branched decahedral seeds. The $\mathrm{pH}$ of a solutions in rows A, B, C, and D are 3.09, 2.87, 2.72, and 2.60 for column 1. The concentration of $\mathrm{NaBr}$ solution was $50 \mathrm{mM}, 70 \mathrm{mM}, 120 \mathrm{mM}$, and $160 \mathrm{mM}$ for columns 1, 2, 3, and 4 , respectively. 


\section{References:}

(1) Chang, C.-C.; Wu, H.-L.; Kuo, C.-H.; Huang, M. H. Hydrothermal Synthesis of Monodispersed Octahedral Gold Nanocrystals with Five Different Size Ranges and Their Self-Assembled Structures. Chem. Mater. 2008, 20, 7570-7574.

(2) DeSantis, C. J.; Sue, A. C.; Bower, M. M.; Skrabalak, S. E. Seed-Mediated Co-Reduction: A Versatile Route to Architecturally Controlled Bimetallic Nanostructures. ACS Nano 2012, 6, 2617-2628.

(3) Weiner, R. G.; Skrabalak, S. E. Metal Dendrimers: Synthesis of Hierarchically Stellated Nanocrystals by Sequential Seed-Directed Overgrowth. Angew. Chem. Int. Ed. 2015, 54, 1181-1184.

(4) Smith, J. D.; Bladt, E.; Burkhart, J. A. C.; Winckelmans, N.; Koczkur, K. M.; Ashberry, H. M.; Bals, S.; Skrabalak, S. E. Defect-Directed Growth of Symmetrically Branched Metal Nanocrystals. Angew. Chem. Int. Ed. 2020, 59, 943-950.

(5) Sánchez-Iglesias, A.; Winckelmans, N.; Altantzis, T.; Bals, S.; Grzelczak, M.; Liz-Marzán, L. M. High-Yield Seeded Growth of Monodisperse Pentatwinned Gold Nanoparticles through Thermally Induced Seed Twinning. J. Am. Chem. Soc. 2017, 139, 107-110. 